\section{Effectiveness of the Direct Instruction Method in Teaching Leisure Skills to Young Individuals with Intellectual Disabilities}

\author{
Emine Eratay*
}

$\begin{array}{ll}\text { Received: } & \text { 24 February } 2020 \\ \text { Revised: } \quad 25 \text { May } 2020 \\ \text { Accepted: } \quad \text { 16 June } 2020 \\ \text { ISSN: 1307-9298 } \\ \text { Copyright (C) IEJEE } \\ \text { www.iejee.com }\end{array}$

DOI: $10.26822 /$ iejee.2020562134

\title{
Abstract
}

This study aimed to examine the effectiveness of the direct instruction method in teaching young individuals with intellectual disability marbling and stone painting, which are considered among leisure-skills. A multiple probe design, one of the single-subject research methods, was utilized in this research. A total of three students, consisting of two males and one female, were included in the study. Probe, screening, and generalization sessions were used to examine the effectiveness of the direct instruction method in teaching marbling and stone-painting skills. The single opportunity method was employed for the assessment. All sessions were conducted in accordance with a one-to-one teaching procedure. The findings of the study revealed that the direct instruction method was effective in teaching marbling and stone painting skills in young individuals with intellectual disabilities. The findings also postulated that the learned skills were maintained at the end of the first, third, and fourth week, and the participants were capable of generalizing the skills to different settings, different people, and materials. To ensure social validity, the opinions of the parents regarding the skills taught to the participants were obtained. They stated that they were satisfied with the intervention and were beneficial for the development of their children. They also expressed that they want these activities to continue. Considering all these findings, it is safe to say that the intervention of teaching marbling and stone-painting skills are effective.

Keywords: Intellectual Disability, Leisure Skills, Marbling, Stone Painting, Direct Instruction Method

\section{Introduction}

Leisure time activities are important not only for school-age children and young individuals with special needs but for all individuals in society. These activities have an important place in the lives of individuals and are suitable for using time efficiently. They are also useful for developing social relations and nourishing the soul. Individuals experience a powerful sense of belonging when they participate in these kinds of activities. This kind of activities improve motor skills and social interaction, which deteriorate at later ages, especially in those with intellectual disabilities They promote better health, making one's own decisions, discovering knowledge and resources, and having a more successful transition from education life to adulthood at their earlier ages. Also, leisure activities are an important tool for the rehabilitation of individuals with intellectual disabilities (Patterson, 2007; Stebbins, 2008).

When IwIDs participate in community-based leisure activities, they develop social interaction with their peers without disabilities, consume their excess energy, and they get the opportunity to have a better quality of life. Activities appropriate for their age contribute to their social relations and physical and mental health, and also accelerate their skill development and improve the perception of being a member of the community they live in. Individual differences were focused on less in group activities; therefore, common interests are shared at higher levels in a group. Leisure time is an essential component for family members and educators in social integration. Unfortunately, IwIDs are not aware of this potential throughout their lives and are mainly engaged in home-based activities on their own, being deprived of participating in group activities (Mahon et al., 2000)

.Kaya (2019) classifies leisure activities for IwIDs as follows: leisure/vocational activities: mirrors, door decoration, making felt crafts (as knick-knackery), relief, origami, kirigami, collage (paper crafts), jewelry design, rug weaving, wattling, knitting, magnet making, candle making, soap making, wood painting, and building models of vehicles; Artistic activities: playing an instrument, solo singing, choir, folk dances (music), drawing, drawing people, themed paintings, marbling, ceramic crafts, photography (visual arts, theater, cinema, drama, and dancing (dramatic arts); Physical/sportive activities: hiking, physical training (physical activities), athletics, basketball, riding, cycling, bowling, darts, football, gymnastics, swimming, skating, tennis, volleyball (sports activities); Social and cultural activities: excursions, special days, picnic, cinema, theater, concert, exhibition, shopping; Entertainment/game activities: various games, technological devices (computers, tablets, and game consoles), storytelling hours, cinematography, and paintball.

When IwIDs participate in leisure/vocational activities, they produce a variety of products and spent quality time. Besides, participating in artistic activities will give them an opportunity to obtain an individual identity, increase their self-confidence to express themselves well, provide motor skills, and enhance their hand-eye coordination. Participation in physical/sportive activities keep their healthy, make them socialized, and motivate them with a sense of accomplishment. While social/cultural activities ensure integration and fitting in society, it was found that participation in entertainment/game activities fosters compliant behaviors and treat problematic ones. It appears that through these activities, IwIDs feel more valuable and tolerant. Besides, some studies claimed that social/cultural activities have positive effects on these aspects, such as building a sense of competition, being a part of a team or a group, and self-confidence (Aksu, 2011; Kaya, 2019; Sukan, 2013; Yaman, 2015).

The study of Dusseljee et al, (2011) examining the status of IwIDs participating in leisure activities revealed that these individuals had difficulty in participating in activities compared to individuals without disabilities and were unable to build social interaction. Zilijstra and Vlaskamp (2005) reported that leisure time activities generally include watching television and listening to music and were mainly performed on weekends. The same study also claimed that there were no 
differences between male and female participants. Lövgren and Bertilsdotter-Rosqvist;, (2015) found that leisure time was related to social and physical activities, well-being, and health. The same study revealed that individuals with disabilities participated less in these activities and benefited less from resources. Baker (2000) asserted that the participation of these individuals in leisure activities was limited and noted that they had problems accessing these activities and they mainly performed these activities alone or with their peers.

Chen et al, (2016) reported that the degree of disability affected participation. In a similar study, Rannikko and Torvinen (2018) argued that the lack of sports activities, transportation facilities, and coaching services in Finland restricted the participation of these individuals in leisure activities. However, Badia et al. (2013) could not find a relationship between quality of life and participation in leisure activities, while stating that participation in these activities was a predictor of emotional and physical well-being. Mactavish and Mahon (2005) claimed that IwIDs preferred individual activities that include learning and exercising that they performed with their free will. They added that these activities had a positive effect on their abilities and attitudes and that they were more satisfied with such activities.

In studies examining the participation of children and young IwIDs in leisure time activities, Melbøe and Yttherhus (2017) found that young individuals of both genders mostly preferred sportive and cultural activities and wanted to participate in activities similar to those that their peers without disabilities do.

Buttimer and Tierney (2005) reported that young individuals in special education schools were alone and passive in their leisure activities and their most preferred activities were watching television, listening to music, eating and drinking activities, walking, listening to radio, making phone calls, shopping, reading magazines, family visits, car trips, and watching movies. They added that the obstacles preventing them from participating in leisure time activities included reasons such as lack of sufficient time or money and suitable locations, being unable to travel, being unable to get their parents' consent, and not knowing how the activity is done.

A study by Solish et al. 2010) asserted that there are differences in the participation of children with and without disabilities in social, recreation, and leisure activities. They also claimed that the socioeconomic status of a family affected their participation, and children with autism spectrum disorder participated in these activities more than children with intellectual disabilities. The same study cited the activities they participated as following: playing games, going to birthday parties, spending time with a friend at home, slumber parties, talking on the phone, and going to shopping centers. King et al., (2005) collected data by applying the Children's Assessment of Participation and Enjoyment and Preferences for Activities of Children scales to children with intellectual disabilities in the age group ranging from six to 15 . Their findings revealed that there was a correlation between the neighborhood, family and child variables, and entertainment and intensity variables and there were differences between gender and age groups.

The study of King et al. (2014) examined the participation of young individuals with severe disabilities in leisure activities and found that activity setting selected by youngsters provided them with a chance for selection, social interaction, social activity, psychological participation, and a sense of belonging to a group and feeling of self-competence. They also stated that passive activities provided these individuals with the opportunity to challenge, select, and develop social interaction.

Bourke-Taylor et al. (2009) developed and applied a scale titled Assistance to Participate Scale measuring leisure time possibilities of 149 children consisting of different disability groups. The findings of the study revealed that there were differences between the participation of children in inclusive and separate schools and activities done alone at home or school and participation rates of disability groups. The researchers also emphasized that children with intellectual disabilities participated in activities such as watching TV, listening to music, playing indoors and outdoors, playing with friends at home, or their friends' houses. Rosner et al. (2004) reported that there is a correlation between age and social competence in the participation in leisure activities of children with Down syndrome. They also stated that these children did not participate in sports activities and mostly preferred musical activities, reading, and doing puzzles. According to Artar (2018), working young IwIDs, in their leisure time, spent time with home-based passive activities.

Artar and Ergenekon (2019) claimed that leisure time is a timeframe that is neglected in adults with developmental deficiencies and that they encountered problems in participating in these activities. Azaiza et al. (2011) reported that cognitive and physical functions played a role in the participation of adults with intellectual disabilities in these activities and that they had lower participation levels. Corders and Howard (2005) conducted interviews with 60 adults with intellectual disabilities and found that they mainly spent time doing activities such as bowling, swimming, watching television or films, and doing handcrafts. The study of Iriarte et al. (2014) examined 168 adults with intellectual disabilities and determined that the participants considered leisure time activities entertaining, and were happy during the activities. Besides, they mainly participated in leisure activities such as watching television, going to the pub, drinking with friends, listening to the radio, playing the accordion, and going on holiday.

Tamar-Weiss et al. (2003) stated that the participation of young individuals with physical and intellectual disabilities in independent activities was limited. However, they highlighted that the participants could learn these activities with help and independent activities increased their skills and self-esteem; therefore, they were of vital importance. Eratay (2013) examined a group of young individuals with moderate intellectual disabilities and found that more than half of the participants did not play sports or participate in any activities, and they were mainly engaged in playing with computer games, singing, drawing, and doing handcrafts. Moreover, none of them were a member of a club or team.

In a study on the effectiveness of programs regarding leisure time activities, Eratay (2013) found that the prepared program was partially effective in the development of social skills and reducing the emotional-behavioral problems of individuals with intellectual disabilities. Karakaş (2018) reported that the 24-week leisure time activity program improved motor efficiency and physical fitness of children with mild intellectual disabilities while Duvdevang (2002) claimed that participation in recreation programs had a positive effect on the perception of physical self-awareness in children with intellectual disabilities in an inclusive education setting. Açıksöz et al. (2016) argued that therapy gardens should be prepared as an activity for individuals with limited intellectual and physical skills; thus, it will be possible for individuals to integrate into society more effectively. In addition, these individuals' deficiencies in self-esteem would be restored and they could establish mutual relationships with normal people and feel nature. Lancioni et al. (2012) stated that technology-supported programs would be more appropriate for these individuals.

Different methods have been conducted to teach IwIDs leisure skills. Studies on the effectiveness of individualized teaching materials are as follows: button sewing (Demir, 1996), sewing (Özokçu, 1997), and canvas embroidery with tapestry needle (Eratay \& Güler Özkan, 2004). Some examples about the effectiveness of simultaneous prompting procedure are as fol- 
lows: stockinet stitching (Çankaya \& Eratay, 2011), overshoe making (Leblebici, 2012), watching educational CDs on computers (Gökmen, Tekinarslan \& Çifçi-Tekinarslan, 2015), foreign language teaching (Çulha, 2010), lawnmowing (Aslan, 2009), stamp collecting (Aslan \& Eratay, 2009), photocopying (Yücesoy-Özkan, Gürsel, 2006), painting patterns on wood and fabric (Özbey, 2005), car washing (Topsakal, 2004), playing bowling (Eldeniz-Çetin \& Çay, 2016), and rhythm tapping with the guitar (Çay \& Özbey, 2016).

Studies on the effectiveness of teaching through video modeling are peeling an orange, drafting stitch, and making origami dogs (Aykut et al., 2014), planting trees (Ulugöl, 2018); cooking pasta (Halisküçük \& Çifçi-Tekinarslan, 2007), marbling (Eldeniz-Çetin \& Ulugöl, 2017), drawing, listening to music, digital photography (Chan et al. 2013); using iPod (Hammond et al., 2010), washing laundry (Horn et al., 2008), making popcorn (Sigafoos et al., 2005), making coffee (Bidwell \& Rehfeldt, 2004), playing basketball, dart air rocket, ball gum, domino, puzzle, and selfie (Cannella-Manole et al., 2016), making bracelets, keyrings, and bookmarkers (Çay \& Eldeniz Çetin, 2018). Studies regarding the effectiveness of constant time delay procedure are playing bowling (Zhang et al., 2004) and carpet weaving (Arslan, 2017). Studies regarding the effectiveness of the direct instruction method are playing tablet and computer games (Elçin \& Kaya, 2016), doing patchworks (Çay, 2019), and social skill-teaching program prepared in line with a creative drama method (Kaya \& Eratay, 2009).

Some studies examined the following teaching leisure skills to children with autism spectrum syndrome: making baskets from clay (Vuran, 2008), teaching basic tennis skills (Yanardağ et al., 2011) regarding the effectiveness of the most to the least prompting; chained task leisure skills (Kurt, 2006), water game skills (Yllmaz et al., 2005), playing card games (Seward et al., 2014) regarding the effectiveness of constant time delay teaching; studies on the effectiveness of teaching with activity schedules (Ünver, 2019; Çuhadar, 2008); studies on the effectiveness of video-model teaching (Blum et al., 2010; Kagohara, 2011); studies on the use of iPod touch (Kagohara et al., 2011; Carlile et al., 2013), basketball, playing with a sticky ball (Altun \& Yücesoy-Özkan, 2018).

Individuals with disabilities learned leisure skills through the aforementioned methods. They also maintained and generalized the skills, and these methods were found to be effective.

Kurt and Coşkun (2018) examined the perceptions of families and teachers on the leisure time activities of IwIDs and reported that families of the adults with intellectual disabilities considered the participation of their children in physical activities inadequate, and they believed that their children did not benefit from these activities sufficiently. However, their perceptions revealed that participation in these activities was very important. In a similar study, Eldeniz-Çetin and Terzioğlu (2017) measured the perceptions of mothers with children with severe disabilities in six and 14 age group. They concluded that these children mostly spent time playing alone or with family members, watching TV, and using their tablets.

Bayram (2016) measured the perceptions of mothers of adolescents with and without intellectual disabilities, and participation of these adolescents in leisure activities was compared that both groups mostly watched TV at home. The researcher also found that individuals without intellectual disabilities participated in social activities more, while those with disabilities spent time with small age group activities with low sociality. Another interesting finding of this study is that the participants without intellectual disabilities mostly did activities with their friends, in contrast, their peers with intellectual disabilities participated in these activities with their mothers and people in their close surroundings. Besides, it was stated that while parents wanted their children to do some outdoor activities with their peers, they were worried about their children because of something bad that could happen to their children.

Çay and Eldeniz (2017) found that a systematic study was not conducted on leisure skills in schools that students with intellectual disabilities attended and teachers working in special education schools. They also argued that these students had limited repertoire of these skills, and the skills are needed to be taught to them, and they mostly spent their leisure time with their friends and families. Çay and Eratay (2019) examined the perceptions of the parents of children with multiple disabilities and reported that these children spent most of their time at home, mainly by watching TV, reading books, listening to music, and using mobile phones. They also noted that they exercised and played games with their parents as well as went to the cinema, had dinner, chatted, praying and traveled together.

Eratay et al. (2017) concluded that ceramics education given to children with disabilities in inclusive education resulted in a partial increase in language skills, and families of children with and without disabilities believed that the program was beneficial for their children. They also emphasized that the families demanded new art activities in inclusive education. Although the educators stated that they were involved in this kind of activity for the first time, all children were easily integrated and successful outputs were achieved in both groups.

In the planning of leisure activities; personnel, material, time management, setting, intervention, and assessment are important issues in terms of the functionality of the activity. In Turkey, there are no institutions or organizations having a complete package providing leisure activities systematically. Services and courses provided by public educational centers and local administrations are limited (Kaya, 2019). Identification of the support necessary in teaching leisure activities to individuals with disabilities, preparation of the individual, provision of education with suitable teaching, the inclusion of repetition to teaching, conducting generalization processes were the reason why skill is considered important (Artar \& Ergenekon, 2019).

When working with students with intellectual disabilities, the level of students must be first determined and preparation work, such as structured and repeated basic artworks, sensory experience like how to use painting brush on paper, activities on how tools or instruments should be used. Then, processes related to developing motor skills and hand-eye coordination should be conducted, and skill analysis must be performed by dividing the skill into small steps in the teaching of the target art skill (Özdemir, 2018).

Creativity can be expressed in line with daily life, work, family life, social interaction, and especially leisure activities. Creative leisure activities support a positive attitude, develop adaptation, help individuals use spare time appropriately, benefit from some additional spefication and achievement. Furthermore, while they mitigate pain, illness, and anxiety, creative leisure activities improve satisfaction and provide access to the social network. When these activities are provided to an individual, the individual's capacity, adaptation, and assistance to the individual must be taken into consideration. Other things that should be taken into consideration are individual's eye contact, mobility, attention span, and cognitive characteristics. If the individual has difficulty in understanding, a suitable format must be determined by information and structuring. Starting with a short and 
simple intervention provides a chance for success that may facilitate focusing on learning. Being a role model may be the right approach. The use of high-quality tools and materials increases the chance of successful output. A suitable distance should be kept with the individual; in addition, the setting and materials must be stimulating If the individual prefers participating in some creative activities with others, his/her access to groups should be facilitated (Creek, 2008).

Marbling art and stone painting are also among the art activities that develop creativity in leisure activities. In marbling art, water concentration is increased with adragant, paint is sprinkled with special brushes, and the patterns on the water are transferred to paper (Arıtan, 1999). Marbling art improves making good use of time, motivation, creativity, patience, and discipline. It also enables stress control, develops self-esteem, motivation, patience, tolerance, understanding, and hand skills. With this activity, children might have peace of mind, develop different perspectives, socialize, and increase their school success (Gür, 2012; Içel, 2014; Kaya, 2012).

In stone art therapy, round stones with smooth surfaces are preferred and painted. The use of different colors is effective in coping with stress. Creative and relaxing activities such as mandala painting, cathartic writing, and drawing help individuals feel better and let them free their minds. With this activity, relaxation, imagination, mental flexibility, improving concentration, and freeing themselves from the burdens of daily problems are attained. Stone art also helps individuals have a great time and improve their artistic skills by opening up an amazing world of possibilities. In stone painting, round stones smoothened by water, acrylic paints, dense acrylic pens, ultra-shiny polishes, and plain brushes are used. Mandalas, animal figures, and entertaining patterns are the most common instruments used in stone-painting designs. Stone art therapy is a preferred intervention and hobby due to its entertaining and economic characteristics (https://sagligabiradim.com/tas-sanati-terapisi-ile-stresi-rahatlatin/ accessed on 26.01.2020)

While stone painting improves children's productivity and aesthetic sense, encountering different materials not only supports their psycho-motor, cognitive, and social developments but also helps develop positive attitudes and behaviors. The stone painting also gives the chance of expressing emotions and thoughts freely, providing an important tool for emotional expression and self-knowledge. Besides, by doing this activity, children develop personality, socialize, and become happy. The most important achievements of stone painting are the development of a sense of aesthetics, creativity, fine motor skills, and hand-eye coordination (https://www.eviminaltintopu.com/tas-boyama-etkinligi/ accessed on 26.01.2020.)

Children and young IwIDs participating in art activities acquire several achievements through these activities. Related studies have shown that simultaneous prompting, activity schedules, constant time delay, and video-modeling are more commonly used methods in teaching leisure skills to IwIDs while teaching with the direct instruction method and teaching of artistic activities is limited. To the best of our knowledge, there is only one study on marbling (Eldeniz-Çetin \& Ulugöl, 2017) and no studies were found on stone painting. Besides, studies on playing games on a tablet or computer and patchwork were found regarding the direct instruction method (Elçin \& Kaya, 2016; Çay, 2019). It is believed that this study has originality in terms of this aspect. It is considered that the study will not only shed light and contribute to educators and new studies but also provide a new viewpoint for parents and educators. The study aimed at examining the effectiveness of the direct instruction method in teaching marbling and stone painting as leisure skills to young IwIDs. The study examined the following research questions:
1. Is the direct instruction method for young IwIDs effective for Aycan, Ferit, and Sefa in teaching marbling and stone-painting skills?

2. Are the skills taught with the direct instruction method to young IwIDs maintained after the first, third, and fourth weeks?

3. Are young IwIDs capable of generalizing the skills they learned with different people, settings, and materials?

4. What are the perceptions (social validity findings) of the parents of the participants on skills acquired by the young individuals as a result of the teaching?

\section{Methodology}

\section{Study Method}

Multiple probe model with an inter-participant probe, one of the single-subject research methods, was used in this study. In this model, the first baseline data were collected simultaneously from all participants. After achieving the stability in the baseline data, the intervention was implemented on the first participant. When the required criterion was met in the intervention, the probe sessions were initiated in all participants, and the data of three consecutive sessions were collected. While the participant who was taught was expected to meet the criteria, the parallelism with baseline data was expected in the two other participants. Following the probe phase, the intervention was conducted on the second participant, and probing was launched on all participants when the criteria were met. While the first and second participants were expected to meet the requirements, the third participant was expected to show parallelism to the baseline data (Tekin-Iftar \& Kırcaali-Iftar, 2004). In this study, experimental control was established with the performance shown by the participants at probing phases being similar to the performance of the participants who were taught the skill in the probe phases.

\section{Study Variables}

The dependent variable of this study is the level of learning of the marbling and stone-painting skills by young IwIDs. The independent variable is the direct instruction method used in teaching marbling and stone-painting skills to young IwIDs.

\section{Direct Instruction Method}

The study adopted the direct instruction method to make students independent in the skill being taught. Before teaching interventions, the content to be taught is organized, and the teaching objectives related to the skill to be taught were determined (Baumann, 1985; Güzel, 1998). Based on clear and written plans, this teacher-centered method is a multi-faceted teaching strategy for assessment (Mitchell, 2008).

The direct instruction method can be used in teaching concepts, processes, or skills to be taught to students. However, students must have prerequisite skills before proceeding to teaching skills (Pearson \& Gallagher, 1983).

1) Rosenshine and Stevens (1986) determined the following six stages analyzing the content of the direct instruction process: Daily review stage: The prerequisite skills required for the skill are reviewed and skill teaching is started.

\section{2) Presentation/modeling stage:}

-Defining the goals of the skill verbally and in writing (e.g., Today we will do marbling with you) 
-Drawing the attention of students and divide the skill into small pieces

-Modeling the skill using a clear and consistent language teacher is showing how to doing the skill by saying "I now take the brush in my hand, dip it into the paint can....")

-Asking questions and making explanations to see whether students understand.

-Providing various examples (We splashed the red paint in the marbling vat first. Now we are splashing the green paint.)

3) Guided practices stage: At this stage, students are expected to adapt to the materials under the guidance and control of their teacher and to achieve $80 \%$ success in every step of the skill. Besides, questions can also be asked during this stage. Verbal clues can be given, and when students become independent in the skill, these clues can be held back. Corrective feedback can be provided by the teacher. At the stage of being a model, the student can try out the skill. At this stage, the student performs the skill by doing more exercises while the teacher observes. If the student is unable to perform the skill, the modeling stage is applied (Güzel, 1998; Mitchell, 2008).

4) Correction and feedback stage: Instant feedback is provided to reduce mistakes.

5) Independent Interventions: At this stage, while students perform the skill, the teacher makes annotations if screening is required. The students should be able to perform the skill independently at this stage, and opportunities should be given to them again. This stage may take longer.

6) Weekly and monthly review stage: Through this stage, students are checked whether the skill is learned or not (Güzel, 1998; Mitchell, 2008).

\section{Participants of the Study}

This section provides information on the observer, implementer, and participants of the study. This study was conducted on a total of three participants, consisting of one female and two males, attending a private special education center located at a central district of a province of the West Black Sea Region in Turkey. Code names were given and used for the participants. Three young individuals who fulfilled the prerequisite skills for marbling and stone-painting skills and diagnosed with mild intellectual disability volunteered to participate in the study. The participants who did not possess these skills were included in the study. Necessary consent forms were obtained before the the study starts, the families of the participants were contacted, and the necessary information was provided regarding the study process. Aycan, Ferdi, and Sefa were used as the code names for the participants.

Prerequisite skills were identified as follows: verbal expression, the minimum attention span of 10 minutes for audio and visual activities, following and imitating motor behaviors, fulfilling verbal instructions, being able to identify colors, and having the necessary hand-eye coordination.

The participants of the study are;

Aycan, attending a special education vocational school, is a 16-year-old female student with mild intellectual disability with a capability of independent self-care, communication, small and big muscle skills, and the modification one or two-step instructions.

Ferdi, attending vocational and technical Anadolu high school, is a 15-year-old male student with mild intellectual disability. He is capable of independent self-care, communication, small and big muscle skills, and the modification one or two-step instructions. He is also capable of mathematics, reading comprehension, and expression skills.

Sefa, attending a special education vocational school, is a 16-year-old male student with mild intellectual disability. He has reading, writing, and mathematics skills. He is capable of independent self-care, communication, small and big muscle, skills, and the modification one or two-step instructions. The students attend a private special education institution after school.

\section{Setting}

The probe, instruction, and maintenance sessions of the study, examining the effectiveness of the direct instruction method in teaching leisure activities to young IwIDs, were conducted in the group education room of the private special education center. The class has a table, chairs, and a cabinet to put the required tools-materials.

\section{Tools-Materials}

The following tools and materials were used in the probe and instruction sessions:

In marbling, an adragant vat, red and blue adragant paints, two brushes, awl, and adragant paper. In stone painting; square stones of $5 \times 5$ dimensions, red stone paint, one brush, thick acrylic paint pen, and spray polish. Yellow and green paints were used in the generalization session for marbling, whereas rectangular stones of $5 \times 10$ dimensions and green paint, thin acrylic paint pen were used in stone painting. Video recordings were made by a student attending the special education section with a video camera. Criterion-referenced test performance-recording form was used for recording the data obtained from the sessions for both marbling and stone-painting activities. The same form was used to record the data collected from the probe and maintenance sessions as well.

\section{Skill Analyses}

In the preparation of skill analysis for marbling and stone-painting skills, a specialist from the drawing department of the university, who is competent in these skills, was consulted, and the pilot interventions were conducted by an implementer. Marbling analysis consists of 12, and the stone-painting skill analysis consists of 14 steps.

\section{Intervention Process}

The study was conducted between March and July in the spring term of 2018-2019. Participants attended their education on weekdays, until 4:30 PM, at their school and came to the private special education institution on weekends, in the afternoons only. The study and intervention were conducted on a one-to-one basis with the three students. Criterion-referenced tests and performance-recording tables were prepared for the skills. Criterion-referenced tests included the statement, question, criteria, and questions. During the assessment, the single opportunity technique was used to determine how much of the target skill they can perform on their own. The sessions were held two days on weekdays and one session each day. The first baseline data were collected for all participants, and once the stable data were obtained, the probe sessions were initiated 
for all participants when the criteria was met for the first participant. When all participants met the criterion, the maintenance, and generalization sessions were started one, three, and four weeks later. First, marbling and then stone-painting skills were taught.

\section{Probe Sessions}

Full and daily probe sessions were held in this study. Full probe sessions of simultaneous three sessions were held for each participant after the participant who was taught to collect the baseline information before the initiation of teaching. Daily probe sessions were organized during the instruction session to constitute the intervention data of the study for the participant who was being taught. A trial was made in each probe session, and this was assessed over $100 \%$ with the reactions given by the participants being taken into consideration in the data collected.

An attention-drawing stimulant like "Now, we will do marbling together. Are you ready?" was given for marbling in the probe sessions. When the participant expressed readiness, skil prompt was given in the form of ". Do marbling." An attention-drawing stimulant was given in the form of "now we will paint stone with you. Are you ready?" for stone painting in the probe sessions. When the participant expressed readiness, verbal reinforcement was made with "well done," now "....... paint the stone" instruction was issued. Response time of five seconds was set for the first step of the skill to be done by the participant, and a response was expected in this period. An A (+) sign was placed on the data collection form in the skill analysis when the skill step was achieved, and an a (-) sign was placed in the event of a wrong response. Sessions were ended when the participant gave an incorrect answer. The probe sessions lasted approximately 10 minutes.

\section{Instruction Sessions}

Marbling instruction sessions were held in the group education room in the private special education institution. A cue was given for marbling like "Now, we will do marbling together. Are you ready?" and reinforcement was provided when the participant expressed their readiness. The participant stood on the right side of the implementer. Marbling materials were prepared on the table in advance. The materials were introduced to the participant, and attention was drawn to the activity. In the modeling phase, the implementer dipped the brushes in the paint containers in front of them, sprinkled this on the adragant container, and shaped it with an awl. The implementer guided the participant by placing the adragant paint on the container, then lifting it and leaving it to dry. During the guided interventions phase, the same skill steps were repeated with guidance. In the independent intervention phase, a "do marbling" skill prompt was given to the participant, and the participant was requested to do the skill without assistance; daily assessments were made after the independent intervention phase. Data regarding the daily assessments of the target skill were obtained at this phase and transferred to a graph.

Stone-painting instruction sessions were also held in the group education room in the private special education institution. A cue was given to the participant to draw attention like "now we will learn stone painting with you. Are you ready?"

Before starting teaching, an unpainted stone, acrylic paint, and acrylic pen were prepared. The implementer stood on the right side of the participant. The materials were introduced to the participant, and attention was drawn to the activity. During the modeling phase, the implementer painted all the surfaces of an unpainted stone with a brush, left it to dry, and made patterns with dashed lines on the previously painted-dried stone with an acrylic pen to model for the participant.
During the guided interventions phase, the same skill steps of the instruction process were repeated with guidance provided to the participants. In the independent interventions phase, "paint the stone" instruction was given to the participant, and he/she was expected to realize the skill without assistance. Daily assessments were made after the independent intervention phase. The data regarding the daily assessments of the target skill were obtained at this phase and transferred to a graph. The instruction sessions lasted approximately 20 - 25 minutes.

\section{Maintenance and Generalization Sessions}

The maintenance sessions of the study were conducted to determine whether the participants could achieve the skills that they learned one, three, and four weeks after the instruction was completed, with the same method used on a one-to-one basis by the researcher with the participants in the probe sessions.

Generalizing sessions of the study were held to determine whether the participants could generalize the skills that they learned with different settings, materials, and people. No cues were given in the generalizing sessions, like in the probe sessions. Generalizing sessions were held in a kitchen in the private special education institution accompanied by an institution's teacher with different materials. The teacher gave the skill prompt like "do marbling" in marbling and "paint the stone" in the stone painting and provided reinforcements at the end of the session saying something like "well done, this is very nice." The maintenance and generalization sessions lasted approximately 20 - 25 minutes.

\section{Reliability}

The inter-observer reliability of the study was calculated with the following formula: "number of agreements / [number of agreements + number of disagreements] 100" (Tekin-Iftar \& Kırcaali-Iftar, 2004). The reliability calculation was made in $30 \%$ of the probe, instruction, maintenance, and generalization sessions of the study. The reliability of the study data was obtained from a lecturer with a doctorate degree, who had been working at the special education department of a university for 25 years and who is competent and experienced in the field of special education. In the study, the reliability percentages for the full probe sessions were $100 \%$ for marbling and stone painting; the inter-observer reliability percentages were $100 \%$ for marbling and stone painting; the inter-observer reliability percentages for maintenance sessions were $100 \%$ for marbling and stone painting; and the inter-observer reliability percentages for generalization sessions were $100 \%$ for marbling and stone painting.

The data collected for the intervention reliability of the study were calculated using the following formula: "observed implementer behavior/planned implementer behavior x 100." (Tekin-Iftar \& Kırcaali-iftar, 2004).

The intervention reliability of the study data was collected in $30 \%$ of the sessions of the study by considering the following issues:
a) Target stimulus
b) Control of tools-equipment
c) Drawing attention
d) Presenting a target stimulus
e) Modeling
f) Doing together
g) Doing independently
h) Reinforcement of student's behavior
i) Feedback/correction 
Intervention reliability of the study data related to all participants and all the behaviors were found as $100 \%$ for marbling and stone painting.

\section{Data Analysis}

The effectiveness of the study data was analyzed with the graphical analysis method. The correct behavior percentages of the participants were shown with equal intervals of 0-100 in two separate graphs with the probe, generalizing, instruction, and maintenance sessions on the horizontal axis and marbling and stone-painting skills, which are the dependent variables of the study on the vertical axis. Whether the experimental control was established in the study or not was determined by only the intervention of the independent variable diachronically to the variability of the dependent variable.

The social validity of the study data was collected from the parents of the participants. The following questions were directed to the parents of the participants, and their answers were assessed with descriptive analysis:

1. What are your opinions on the activity applied to your child?

2. What are your opinions on the skills applied to your child?

3. What kind of benefits will this activity provide for your children?

4. Is there anything you want to add?

\section{Findings}

This part summarized that the findings on the effectiveness of the direct instruction method in teaching marbling and stone-painting skills to young IwIDs and the maintenance and generalization of the skills.

Findings on the Effectiveness of the Direct Instruction Method in Teaching Marbling skill

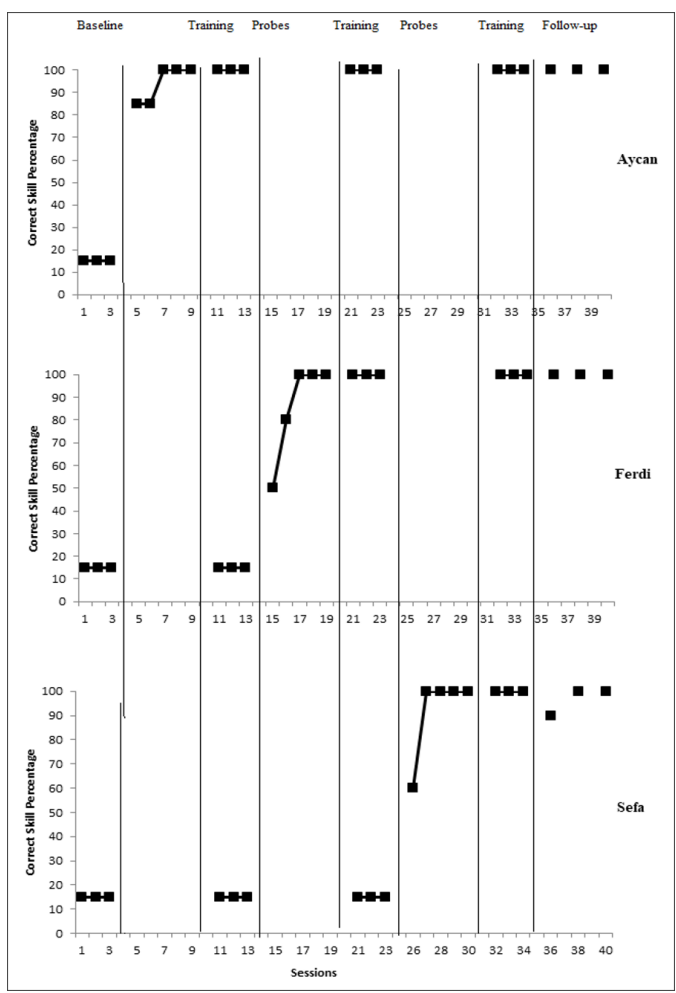

Figure 1. Marbling Data

\section{Aycan}

Aycan achieved 15\% performance in the baseline sessions. When the stable data were obtained in the baseline data, instruction sessions were initiated. Five instruction sessions were held in teaching the skill, which was continued until the criterion was met at the level of $100 \%$. In the probe sessions after the instruction sessions, skill steps were conducted with a $100 \%$ success in the generalization and maintenance sessions. Under the light of these findings, it is seen that Aycan acquired, maintained, and generalized the skill of marbling with the direct instruction method.

Ferdi

Five instruction sessions were held with Ferdi. He achieved $15 \%$ performance in the baseline sessions that were held before the launch of the instruction. This rate increased to $100 \%$ at the end of the instruction sessions. No changes have occurred in the success status of Ferdi in the probe sessions held after the instruction sessions. The success level was $100 \%$ in the maintenance data and generalization sessions. Considering these findings, it is seen that Ferdi acquired, maintained, and generalized the skill of marbling with the direct instruction method.

\section{Sefa}

Five instruction sessions were held with Sefa. He attained $15 \%$ performance in baseline sessions. This rate increased to $100 \%$ after the second instruction session. The success level was $100 \%$ in the maintenance and generalization sessions achieved after the instruction sessions. Under the light of these findings, it is seen that Sefa acquired, maintained, and generalized the skill of marbling with the direct instruction method.

Findings on the Effectiveness of the Direct Instruction Method in Stone-painting Skill

The data obtained regarding the teaching of stone-painting skills for all participants are presented in Figure 2.

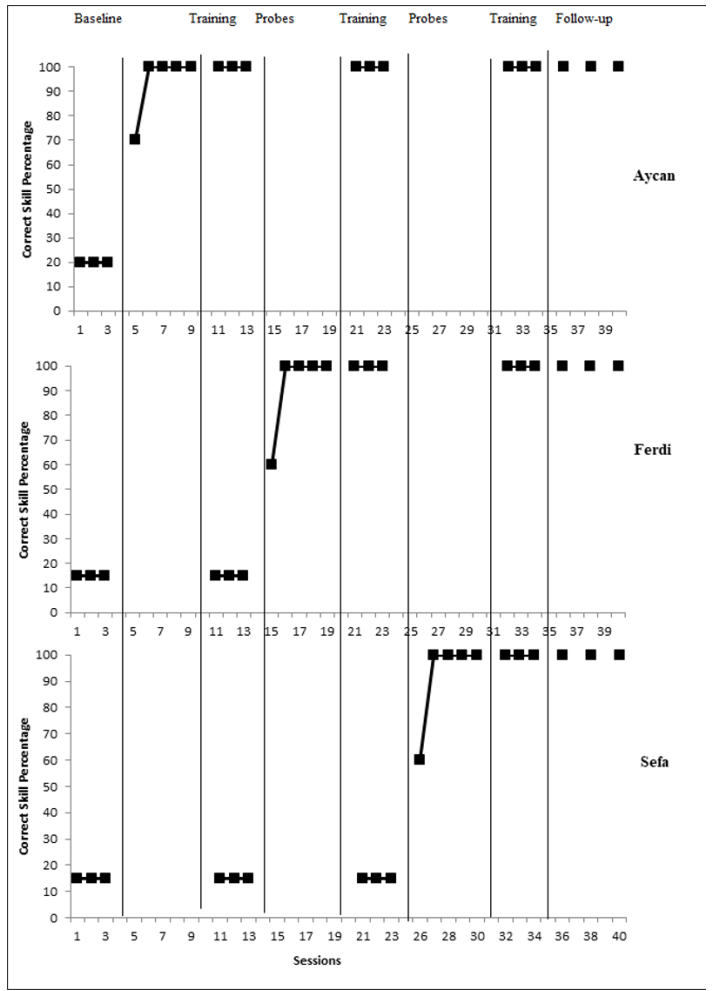

Figure 2. Stone-painting Data 


\section{Aycan}

Aycan presented $15 \%$ performance in the baseline sessions. When the stable data were obtained in the baseline data, the instruction sessions were started. Five instruction sessions were held with her, and it was seen that the criterion was met at a $100 \%$ level. A drop was seen in the following full probe data in the success level. The success level was $100 \%$ in the maintenance and generalization sessions. The findings depicted that Aycan acquired, maintained, and generalized the skill of stone painting with the direct instruction method.

\section{Ferdi}

Five instruction sessions were held with Ferdi. He attained 15\% performance in the baseline sessions, and it was seen that he met the criterion at a $100 \%$ level in the first session held after the stable data were obtained. Skill steps were realized with a $100 \%$ success in the full probe sessions. His success level was $100 \%$ in the maintenance and generalization sessions held after the instruction sessions. The findings depicted that Ferdi acquired, maintained, and generalized the skill of stone painting with the direct instruction method.

\section{Sefa}

Five instruction sessions were held with Sefa. He attained 15\% performance in the baseline data, and it was seen that he met the criterion at a $100 \%$ level in the first teaching session after the stable data were obtained. Sefa achieved a $100 \%$ success in the maintenance and generalization sessions. The findings revealed that he acquired, maintained, and generalized the skill of stone painting with the direct instruction method.

In addition to the findings given above, the implementer observed that all participants were happy during the intervention of the skills and performed their skills happily and willing ly. The participants would say "Please start with me first" at the interventions of the study. When attaining the skills steps of the instruction sessions, Ferdi also expressed his happiness verbally. For example, "I am now dipping my brush in the paint, sprinkling my paint on the tray, and making shapes," "first, I am painting the front face, .... Now I am drawing my lines with the pen, polishing."

\section{Social Validity Findings}

A social validity form, consisting of four questions, was created in consultation with a specialist to obtain findings related to the social validity of the study, and these were applied to the parents of the participants with the interview method. The interviews were conducted at the end of the intervention by the implementer of the study in the principal's room of the institution. Aycan's father and Ferdi and Sefa's mothers participated in the interviews. The interviews took 15-20 minutes

\section{Opinions of the Parents on the Intervention}

1. "It was a good intervention; I am pleased, it took her one step further."

2. "I am satisfied. It was a different kind of fun for him. He came here happily and willingly. I am very pleased. His skills have developed."

3. "It was very nice for his. It prevented his from closing himself at home. It was very good for him.

Opinions of the Families on the Skills Applied

1. "She was very restricted; the intervention helped her eliminate these restrictions. It helped her improve writing skills and made progress."
2. "They were very good activities that helped him develop; they guided him and developed his creativity."

3. "He does not talk much about what he did, but both activities were nice and beneficial."

Opinions of the Families on the Kinds of Benefits Provided by the Intervention to Their Children

1. "Contributed to her reading and writing skills, I do not see any missing issues. It was very useful for the future. I hope she becomes an artist. It helped her make great progress."

2. "Drawing and art activities are not provided at school very much. I really want these activities to continue and help my child develops if he has talent."

3. "The activities have increased his self-confidence. He mainly spent his time on the computer. I am very happy that he is engaged in a different activity. These activities prevented her from getting bored at home and reduced his ill-temper."

\section{Discussion}

This study examines the impact of the direct instruction method on teaching marbling and stone painting as leisure skills to young IwIDs. The study also examines whether the learned skills are maintained one, three, and four weeks after teaching and whether the taught skills can be generalized to different people, settings, tools, and equipment.

Study findings indicate that the participants acquired the skills regarding marbling and stone painting and maintained their skills and generalized them with different people, settings, and tools-equipment. As Figure 1 and Figure 2 depict, the number of instruction sessions of the participants is close to each other. To ensure that the participants can perform to meet the criterion, it can be said that individuals with similar cognitive characteristics were selected in terms of prerequisite conditions during the selection of the participants. The literature review showed that studies were conducted on the effectiveness of individualized teaching materials in the teaching of leisure skills to IwIDs (Demir, 1996; Özokçu, 1997; Eratay \& Güler-Özkan, 2004). Even though the analyses of the study were conducted with a different method, there are similarities between the findings in terms of partial effectiveness.

Moreover, the participants learned, maintained, and generalized the skills in the studies in which leisure skills were taught to IwIDs with the simultaneous prompting procedure in the single-subject research model (Çankaya \& Eratay, 2011; Leblebici, 2012; Gökmen, Tekinarslan \& - Çifçi Tekinarslan, 2014; Çulha, 2010; Aslan, 2009; Aslan \& Eratay, 2009; Yücesoy-Özkan \& Gürsel, 2006; Özbey, 2005; Topsakal, 2004, Eldeniz-Çetin \& Çay, 2016). In this aspect, the findings of this study are in line with the findings of the studies on the effectiveness of simultaneous prompting procedure. Also, in studies in which video-modeling was used for teaching leisure skills to IwIDs, the participants learned, maintained, and generalized the skills (Aykut et al., 2014; Ulugöl, 2018; Eldeniz-Çetin \& Ulugöl, 2017; Chan et al., 2013; Hammond et al., 2010; Zhank et al. 2004). The study findings have some similarities with the results of the aforementioned studies in this aspect.

Moreover, the findings of this study have a partial similarity with the findings of the study on the effectiveness of activity schedules in IwIDs (Arslan, 2017) and studies in which leisure skills were taught to children with autism spectrum disorders using the errorless teaching method. 
It is safe to say that studies on teaching leisure skills were mainly conducted using multiple probe design with probe conditions across participants of the single-subject research model. This study has similarities and parallelism with other studies in terms of this aspect as well.

Eldeniz-Çetin and Ulugöl (2017) taught marbling skill, which was taught with the direct instruction method in this study, to young IwIDs with video modeling. It is interesting that even though the same skill was taught with different methods, the individuals acquired, maintained, and generalized this skill, so it is also possible to say that there is parallelism here.

Studies on teaching playing games on a tablet or computer (Eliçin \& Kaya, 2016) and fixing blown tires (Çay, 2019) to IwIDs with the direct instruction method have similarities and overlap with the findings of this study in terms of the effectiveness of the direct instruction method.

The findings of studies examining the opinions of the teachers and parents on leisure activities revealed that adequate activities for these individuals were not available at schools (Çay \& Eldeniz-Çetin, 2017); successful results were obtained from the activities that children benefitted (Eratay et al., 2016); and that children mostly spent time at their homes (Çay \& Eratay, 2019; Eratay, 2013; Bayram, 2016). Regarding the social validity findings, the parents stated that they were very happy with the activity because they thought it contributed to the development of their children. They also expressed that the intervention was beneficial, and there were no such activities in their schools. Social validity findings support the findings of Çay \& Eldeniz-Çetin (2017), Eratay et al., (2016), Çay \& Eratay (2019), Eratay (2013), and Bayram (2016).

In the study, the parents stated that the aggressiveness of their children mitigated, their children were bored at home and that the activity increased their self-confidence. These findings of this study support the studies and opinions that leisure activities promote trust and courage and provide behavioral therapy (Aksu, 2011; Kaya, 2019; Sukan, 2013; Yaman, 2015). Moreover, Ferdi expressed the skill steps verbally during the sessions. This finding is consistent with the findings of Aksu (2011) that artistic activities improve the ability of self-expression.

Some studies postulated that the participation of IwIDs in leisure activities is limited (Dusseljee et al., 2011; Ziljstra \& Vlaskamp, 2005; Bertilsdotter-Rosqvist, 2015; Armila, Rannikko \& Torvinen, 2018). This study could be argued to be important in terms of providing an opportunity for these young individuals with limited participation in these activities. At the end of the study, the skill tools and equipment used in the study were gifted to the institution to provide an opportunity to use them for other individuals who were not included in this study.

Mactavish \& Mahon (2005) claim that individual-oriented activities are more satisfying for these individuals. The fact that the children were highly motivated in the study, they were very happy with the activity, and the individual-orientedness of the activity supports the opinions of Mactavish \& Mahon (2005).

Conclusion

The study examined the effectiveness of the direct instruction method in teaching marbling and stone painting as leisure skills among young IwIDs. The inter-observer reliability of the study was $100 \%$ for full probe, daily probe, maintenance, and generalization sessions in marbling and stone painting. The implementation reliability of this study was
$100 \%$ for all participants and behaviors. The participants learned the marbling and stone-painting skills taught with the direct instruction method, and maintenance and generalization were attained. As for the social validity findings, the parents stated that they were very happy with the activity and that it was beneficial for their children.

The use of the direct instruction method and a small number of participants may be a limitation of the study. Regarding the recommendations on the intervention, it can be recommended that the direct instruction method is used in the teaching of leisure skills by IwIDs' teachers. Different leisure time skills such as glass mosaic making, kite making, glass painting, and macramé making can be taught through this method. The research was conducted in an individual study class in a private education center. Considering that it was an artistic study, some difficulties were encountered in the classroom from time to time. Such a study can be better conducted in a workshop class. The painted papers removed from the vat during the marbling works were dried on the radiators. From time to time, paint dripped from the paper. At the end of the study, the implementer cleaned the paint stains on the floor. As the paints used during the interventions were selected from the paints, they did not leave a stain on the floor and come out quickly when washed or wiped with a wet towel. During the research, there was no stain on students' clothes. However, aprons and gloves can be used in marbling and stone-painting activities. Some of the study products were given to students when they were dry, and they were allowed to take them home. Some products were delivered to the institution to be placed in the students' files. However, the study could not be exhibited because the end of the study coincided with a holiday. It is important that students' work is to be presented to teachers, parents, and other visitors. The products of the intervention can be exhibited. A very simple method was employed in marbling. More complex patterns, such as tulip making, can be implemented. In stone painting; square and rectangular stones and line drawing on the stone were used. With different stones, for example, oval, circle stones, or large size stones, animal figures, mandala patterns can be examined. In future studies, marbling and stone-painting skill may be taught with the direct instruction method to children with different disabilities and in different settings or as individual and group teaching. Leisure skills may be obtained through different methods. In addition, at the end of the study, the materials and equipment used in the study were given to the institution as gifts for the use of other individuals. The teaching of artistic activities can be added to the school curricula so that neglected leisure time activities can be compensated. Programs for teaching leisure activities for teachers and families can be organized. Free time activities where families and young people attend can be arranged (For example, the whole school is going on a picnic together, parents and young people attending a drama event). In this research, individual education was provided. Future studies should examine the activities in which young people with and without disabilities participate together in inclusion settings. In this study, The perceptions of the parents were collected. Future studies may examine the perceptions of teachers and participants. The direct instruction method used in teaching leisure skills may be used with other methods to compare their effectiveness and efficiency.

\section{References}

Açıksöz, S., Bollukçu, P., Cengiz Gökçe, S. \& Yar, Z.S. (2016). Therapy gardens for individuals with mental disability: special care centers example. International Science and Technology Conference. Vienna-Austria, July 13-15, 2016. (ISTEC). 
Aksu, M. (2011). The contribution of visual arts education to the development of motor skills for mentally handicapped children. (Unpublished master's thesis), Bursa Uludağ University. Bursa, Turkey.

Altun, D.E. \& Yücesoy-Özkan, Ş. (2018). Comparison of video prompting with error correction and without error correction in the teaching of leisure time skills. Ondokuz Mayıs University Education Faculty Journal. 37(2). 15-33. doi: 10.7822/omuefd. 357700.

Arıtan, A.S. (1999). Turkish art of marbling and its current situation. Selçuk University Institute of Social Sciences Journal, 5. 441-469.

Armila, R., Rannikko, A. \& Torvinen, P. (2018). Young people with intellectual disabilities and sport as a leisure activity: notions from the Finnish welfare society. Leisure Studies, 37(3). 295-306.

Arslan, E. (2017). The effectiveness of teaching making with activity-schedule to the students who are intellectual disability in teaching carpet weaving skill (Unpublished master's thesis). Abant İzzet Baysal University. Bolu, Turkey.

Artar, T.M. \& Ergenekon, Y. (2019). An ignored period of time for adults with developmental disabilities: leisure time. Ankara University Faculty of Educational Sciences Journal of Special Education, 20, 1-22. doi: 10.21565/ozelegitimdergisi. 559802.

Artar, T.M., (2018). Coworkers' views and suggestions about working life of individuals with intellectual disability (Unpublished master's thesis). Anadolu University. Eskişehir, Turkey.

Aslan, T. (2009). The efficacy of teaching with simultaneous prompting in teaching of the skill of mowing with electrical mower to individuals with mental retarded (Unpublished master's thesis). Abant İzet Baysal University, Bolu, Turkey.

Aslan, Y. \& Eratay, E. (2009). Effectiveness of teaching with simultaneous prompting in teaching the skill of sequin embroidering on a pattern drawn on fabric for individuals with mental disability. Ankara Üniversitesi Eğitim Fakültesi, Özel Eğitim Dergisi. 10(2). 15-34.

Aykut, Ç., Dayı, E., Emecen-Dağseven, D. \& Karasu, N. (2014). Acquisition of chain skills by students with mental disability in small groups with video prompting. Education Sciences in Theory and Practice, 14(3), 1075-18087.

Badia, M. Orgaz, M.B., Verdugo, M.A., Ullan, A.M. \& Martinez, M. (2013). Relationships between leisure participation and quality of life of people with developmental disabilities. Journal of Applied Research in Intellectual Disabilities, 26, 533-545.

Baker, P.A. (2000). Measurement of community participation and use of leisure by service users with intellectual disabilities: the Guernsey community participation and leisure assessment (Gcpla). Journal of Applied Research in Intellectual Disabilities, 13, 169-185.

Bayram, E. (2016). Assessment for format of leisure time of adolescents with or without intellectual disability (Unpublished master's thesis). Abant İzzet Baysal University. Bolu, Turkey.
Baumann,J.F (1985). The direct instruction of reading comprehension skills: A teacher - directiveness paradigm. The Annual Meeting of National Reading Conference, December:1-6.San Diego. (ED 237 931).

Bildwell, M.A. \& Rehfeldt, R.A. (2004). Using video modelling to teach a domestic skill with an embedded social skill to adults with severe mental retardation. Behavioural Interventions, 19, 263-274.

Bourke-Taylor, H., Law, M., Howie, L. \& Pallant, J.F. (2009). Development of the assistance to participate scale (aps) for children's play and leisure activities. Child: Care, Health and Development, 35(5), 738-745. doi: 10.1111/j. 1365-2214.2009.00995.x

Buttimer, J. \& Tierney, E. (2005). Patterns of leisure participation among adolescents with a mild intellectual disability. Journal of Intellectual Disabilities, 9(1), 25-42. doi: 10.1177/1744629505 049728

Canella-Malone, H.I., Miller, O., Schaefer, J.M., Jimenez, E.D. Justin, E. \& Sabielny, L.M. (2016). Using video prompting to teach leisure skills to students with significant disabilities. Exceptional Children, 82(4), 463-478.

Carlie, K.A., Reeve, K.F. \& DeBar, R.M. (2013). Using activity schedules on the iPod touch to teach leisure skills to children with autism. Education and Treatment of Children, 36(2), 33-52.

Chan, J.M., Lambdin, L., Van Laarhoven, T. \& Johnson, J.W. (2013). Teaching leisure skills to an adult with developmental disabilities using a video prompting intervention package. Education and Training in Autism and Developmental Disabilities, 48(3), 412-420.

Chen, Y.M., Chiang, T.L., Chen, D.R., Tu, Y.K. \& Yu, H.W. (2016). Trajectories of older adults' leisure time activity and functional disability: a 12-year follow-up. International Society. Of Behavioural Medicine, 23, 697-706. Doi: 10.1007//s.12529-016-9554-y.

Cordes, T.L. \& Howard, R.W. (2005). Concepts of work, leisure, and retirement in adults with an intellectual disability. Education and Training in Developmental Disabilities, 40(2), 99-108.

Creek, J. (2008). Creative leisure opportunities. Neuro Rehabilitation, 23, 299-304.

Çankaya, Ö. \& Eratay, E. (2011). Effectiveness of simultaneous prompting on teaching stockinette stitching skill to students with mental retardation. Abant izzet Baysal Üniversitesi Eğitim Fakültesi Dergisi, 11(2), 11-34.

Çay, E. \& Eldeniz-Çetin, M. (2018). The effectiveness of video prompting in small groups teaching of leisure skills to individuals with intellectual disabilities. International Online Journal of Educational Sciences, 10(4), 18-37.

Çay, E. \& Eratay, E. (2019). The opinions of the parents who have children with multiple disabilities regarding leisure time activities. Ulusal Eğitim Akademisi Dergisi. UEAD, 3(2), 158-184.

Çay, E. \& Özbey, F. (2016). Effectiveness of simultaneous prompting in teaching rhythm tapping with a guitar to students with intellectual disability. VII. Hisarlı Ahmet Sempozym oral presentation, Kütahya, Turkey. 
Çay, E. (2019). The effectiveness of direct instruction procedure on teaching vocational skills to students with intellectual disabilities. Uşak Üniversitesi Eğitim Araştırmaları Dergisi, 5(1), 1-21.

Çuhadar, S. (2008). Effectiveness of the instruction realized through activity schedules on leisure skills of children with autism (Unpublished doctoral thesis). Anadolu University. Eskişehir, Turkey.

Çulha, S. (2010). The effect of individual supportive education applying by simultaneous prompting in teaching foreign language for the primary school inclusive education students with intellectual disabilities (Unpublished master's thesis). Anadolu University, Eskişehir, Turkey.

Demir, H. (1996). Effect of materials for teaching sewing button skill by modelling and verbal prompting to teach button sewing skills to the students with intellectual disability (Unpublished master's thesis). Gazi University, Ankara, Turkey.

Duvdevany, I. (2002). Self-concept and adaptive behaviour of people with intellectual disability in integrated and segregated recreation activities. Journal of Intellectual Disability Research, 46(5), 419-429.

Eldeniz Çetin, M. \& Çay, E. (2016). The effectiveness of simultaneous prompting procedure on teaching bowling skill to students with intellectual disabilities. The Journal of Social Science, 3(9), 441-455.

Eldeniz-Çetin, M. \& Çay, E. (2017). Identification of teacher's opinions on leisure time skills of students with intellectual disability. The Journal of Kesit Academy, 3(10), 732-755.

Eldeniz-Çetin, M. \& Terzioğlu, N.K. (2018). Opinions of mothers with severe deficiency on making use of leisure time by their children. Abant Izzet Baysal Üniversitesi Eğitim Fakültesi Dergisi, 18(2), 857-873.

Eldeniz-Çetin, M. \& Ulugöl, F. (2017). Effectiveness of video modelling on marbling skill teaching for individuals with intellectual disabilities. Atatürk Üniversitesi Kazım Karabekir Eğitim Fakültesi Dergisi, 35, 234-251.

Eliçin, Ö. \& Kaya, A. (2016). Teaching game playing skills on the tablet computer with the direct instruction method to individuals with intellectual disability. Boğaziçi Üniversitesi Eğitim Dergisi, 33(2), 1-19.

Eratay, E. \& Güler-Özkan, A. (2004). Effectiveness of individualized teaching material for teaching embroidery with tapestry needle to school-age children and young individuals by physical assistance and verbal prompting. XIII. Ulusal Özel Eğitim Kongresi Bildirgeleri. Ankara: Kök Yayıncılık. 177-187.

Eratay, E. (2013). Effectiveness of leisure time activities program on social skills and behavioral problems in individuals with intellectual disabilities. Educational Research and Reviews, 8(6), 1437-1448. doi:10.5897/ ERR2013.1509.

Eratay, E. (2013). Study on the leisure time activities of young individuals with intellectual disability. I. Ulus/ararası iş ve Meslek Danışmanlı̆̆ı Kongresi. 28-29 Kasım 2013. Ankara: İşkur Yayınları.
Eratay, E., Aydoğan, Y., Altundağ, M. \& Ural, M. (2017). Effectiveness of ceramic training given to preschool children with and without mental disability. Trakya Üniversitesi Sosyal Bilimler Dergisi, 19(1), 351-369.

Gökmen, C., Tekinarslan, E. \& Çifçi-Tekinarslan, İ. (2015). The effectiveness of simultaneous prompting procedure on teaching the skill of watching instructional cd on the computer to students with intellectual disabilities. Abant Izzet Baysal Üniversitesi Eğitim Fakültesi Dergisi, 15, 190-217.

Gür, Ç. (2012). Turkish marbling and gifted children. International Journal of Learning and Development, 2(6), 86-92.

Güzel, R. (1998). Effectiveness of individualized reading comprehension material presented with the direct teaching method in teaching comprehension skills for stories they read out aloud in special classes (Unpublished doctoral thesis). Gazi University, Ankara, Turkey.

Halisküçük, E.S. \& Çifçi-Tekinarslan, İ. (2007). The effect of video modelling to children with mentally retarded on teaching ability of cooking macaroni. Abant izzet Baysal Üniversitesi Eğitim Fakültesi Dergisi, 7(2), 113129.

Hammond, D.L., Whatley, A.D., Ayres, K.M. \& Gast, D.L. (2010). Effectiveness of video modelling to teach "iPod" use to students with moderate intellectual disabilities. Education and Training in Autism and Developmental Disabilities. 45(4). 525-538.

Horn, J.A., Miltenberger, R.G., Weil, T., Mowery, J., Conn, M. \& Sams, L. (2008). Teaching laundry skills to individuals with developmental disabilities using video prompting. International Journal of Behavioral Consultation \& Therapy, 3(4), 279-286.

Iriart, E.G., O'Brien, P., McConkey, R., Wolfe, M. \& O'Doherty, S. (2014). Identifying the key concerns of Irish persons with intellectual disability. Journal of Applied Research in Intellectual Disabilities, 27, 564-575.

Kagohara, D., Sigafoos, J., Acmadi, D. Van Der Meer, L., O'Reilly, M.F. \& Lancioni, G.E. (2011). Teaching students with developmental disabilities to operate in iPod touch to listen to music. Research in Developmental Disabilities, 32, 2987-2992.

Kagohara, D.M. (2011a). Three students with developmental disabilities learn to operate an iPod to access age-appropriate entertainment videos. Journal of Behavioural Education, 20, 33-43.

Karakaş, G. (2018). The effect of leisure activities applied to mild intellectual disabled children on their physical fitness and motor development (Unpublished doctoral thesis). Sakarya Üniversitesi. Sakarya, Turkey.

Kaya, A. (2019). Leisure time activities. Adults with intellectual disability. Cavkaytar, A., Kaya, A. (Eds). Ankara: Eğiten Kitap. 154-174.

Kaya, D., Eratay, E. (2009). The effects of creative drama method on the development of social skills of adults with mental disabilities. Yaratıc Drama Dergisi, 4(8), 53-75.

Kaya, S. (2012). Role of marbling art on children and Düzce Istibal Kindergarten example. Akdeniz Sanat Dergisi, 10, 45-54. 
King, G.A., Law, M., King, S., Hurley, P., Hanna, S., Kertoy, M. \& Rosenbaum, P. (2005). Measuring children's participation in recreation and leisure activities: construct validation of the cape and pac. Child: Care, Health and Development, 33(1), 28-39. doi: 10.1111/j. 13652214.20606.00613.x

Kurt, O. (2006). A comparison of constant time delay and simultaneous prompting within embedded instruction on teaching chained leisure skills to children with autism (Unpublished doctoral thesis). Anadolu University. Eskişehir, Turkey.

Kurt, Ö. \& Coşkun, İ. (2018). Examination of physical activity level of children of families with an adult member with mental disability. Balkan and Near Eastern Journal of Social Sciences, 4(3), 1-9.

Lancioni, G.E., Singh, N.N., O'reilly, M.F., Green, V., Oliva, D., Bounocunto, F., Sacco, V. Biancardi, E.M., \& Di Nuovo, S. (2012). Technology-based programs to support forms of leisure engagement and communication for persons with multiple disabilities: Two single-case studies. Developmental Neurorehabilitation, 15(3),. 2092018.

Leblebici, T. (2012). The effectiveness of simultaneous prompting on teaching making overshoe skills to students with mental disabilities (Unpublished master's thesis). Dokuz Eylül University, İzmir, Turkey.

Lövgren, V., Bertilsdotter-Rosqvist, H. (2015). More time for what? Exploring intersecting notions of gender, work age, and leisure time among people with cognitive disabilities. International Journal of Social Welfare, 24, 263-272. Doi: 10.1111/ijs. 12135.

Mactavish, J. \& Mahon, M.J. (2005). Leisure education and later-life planning: a conceptual framework. Journal of Policy and Practice in Intellectual Disabilities, 2(1), 29-37.

Mahon, M.J., Mactavish, J. \& Bockstoel, E. (2000). Making friends through recreation. Social integration, leisure, and individuals with intellectual disability. $P \& R$, April. 25-40.

Melbøe, L. \& Yttherhus, B. (2017). Disability leisure: in what kind of activities, and when and how do youths with intellectual disabilities participate? Scandinavian Journal of Disability Research, 19(3), 245-255.

Mitchell, D. (2008). What really works in special and inclusive education. USA: Routledge. 188-195.

Özbey, F. (2005). The effectiveness of simultaneous prompting procedure on teaching vocational skill to students with mental retardation (Unpublished master's thesis). Abant İzzet Baysal Universitesi. Bolu, Turkey.

Özdemir, O. (2018). Drawing-craft art skills in children with special needs. In. Özel eğitimde sanatsal becerilerin öğretimi. Toper, Ö. (Ed.). 2. Baskı. Ankara: Vize Akademik.

Özokçu, O. (1997). Effectiveness of individualized materials for teaching sewing skill by modelling and verbal prompting to teach sewing skills to the students with intellectual disability (Unpublished master's thesis). Gazi University, Ankara, Turkey.
Patterson, I. (2007). Leisure education for special groups. In the pivotal role of leisure education. Finding personal fulfilment in this century. Cohen-Geverc, E., Stebbins, R.A. (Eds). Pennsylvania: Venture Publishing. Inc

Pearson, P.D. \& Galllagher,M.C. (1983). The instruction of reading comprehension. Contemporary Educational Psychology, 8, 317-344.

Rosenshine, B. \& Stevens, R. (1986). Teaching functions. In M. C. Witrock (Ed). Handbook of research teaching (3 rd. ed). New York: Macmillan. 376-391.

Rosner, B.A., Hodapp, R.M., Fider, D.J., Sagun, J.N. \& Dykens, E.M. (2004). Social competence in persons with prader-willi, Williams, and down.'s syndromes. Journal of Applied Research in Intellectual Disabilities, 17, 209-217.

Seward, J., Schuster, J.W. Ault, M.J., Collins, B.C. \& Hall, M. (2014). Comparing simultaneous prompting and constant time delay to teach leisure skills to students with moderate intellectual disability. Education and Training in Autism and Developmental Disabilities, 49(3), 381-395.

Sigafoos, J., O’Reilly, M., Cannella, H., Upadhyaya, M., Edrisinha, C., Lancioni, G.E., Hundley, A., Andrews, A. Garver, C. \& Young, D. (2005). Computer-presented video prompting for teaching microwave oven use to three adults with developmental disabilities. Journal of Behavioural Education, 3(14), 189-201.

Solish, A., Perry, A. \& Minnes, P. (2010). Participation of children with and without disabilities in social, recreational, and leisure activities. Journal of Applied Research in Intellectual Disabilities, 23, 226-236.

Stebbins, R.A. (2008). Right leisure: serious, causal, or project-based? Neuro Rehabilitation, 23, 335.341.

Sukan, H.D. (2013). The effect of physical activity on socialization of children with intellectual disabilities (Unpublished master's thesis). Muğla Sıtkı Koçman University. Muğla, Turkey.

Tamar-Weiss, P., Bialik, P. \& Kizony, R. (2003). Virtual reality provides leisure time opportunities for young adults with physical and intellectual disabilities. Cyber Psychology \& Behavior, 6(3),. 335-342.

Tekin-Iftar, E. \& Kırcaali-iftar, G. (2004). Errorless teaching procedures in special education. (2nd. Ed.)] Ankara, Turkey: Nobel Yayınevi.

Topsakal, M. (2004). Effectiveness of simultaneous prompting with error correction for teaching car washing skills to the children with mental disability (Unpublished master's thesis). Anadolu University. Eskişehir, Turkey.

Ulugöl, F. (2018). The effectiveness of video modelling in teaching farming skills to individuals with intellectually disabled (Unpublished master's thesis). Abant İzzet Baysal University. Bolu, Turkey.

Ünver, M. (2019). The effectiveness of activity schedules presented via tablet while families are doing leisure time activities to the children with autism spectrum disorder (Unpublished master's thesis). Anadolu University, Eskişehir, Turkey.

Vuran, S. (2008). Empowering leisure skills in adults with autism: An experimental investigation on through the most to least prompting procedure. International Journal of Special Education, 23(1), 174-181. 
Yaman, T. (2015). Research on the effects of physical education and games on the acquisition of social skills of individuals with intellectual disabilities (Unpublished master's thesis). Mehmet Akif Ersoy University. Burdur, Turkey.

Yanardağ, M., Birkan, B., Konukman, F., Agbuga, B. \& Lieberman, L. (2011). The effects of least-to-most prompting procedure in teaching basic tennis skills to children with autism. Kinesiology: International Journal of Fundamental and Applied Kinesiology, 4(1), 44-55.

Yılmaz, I., Birkan, B., Konukman, E. \& Erkan, M. (2005). Using constant time delay procedure to teach aquatic play skills for with autism. Education and Training in Autism and Developmental Disabilities, 40(1), 171-182.

Yücesoy-Özkan, Ş. \& Gürsel, O. (2006). Effectiveness of teaching photocopying skills with the simultaneous prompting to students with intellectual disability. Ankara Üniversitesi Eğitim Bilimleri Fakültesi Özel Eğitim Dergisi, 7(2), 29-45.

Zhang, J., Cote, B., Chen, S. \& Liv, J. (2004). The effect of a constant time delay procedure on teaching adults with severe mental retardation a recreation bowling skill. Physical Educator, 61(2), 63-74.

Ziljstra, H.P., Vlaskamp, C. (2005). Leisure provision for persons with profound intellectual and multiple disabilities: quality or killing time? Journal of Intellectual Disability Research, 49(6), 434-448. Doi: 10.1111/ j.1365-2788.2005.00 689.x

www.sagligayardim.com.(2020;January.26).Retriewed from https://sagligabiradim.com/tas-sanati-terapisi-ile-stresi-rahatlatin/

www.eviminaltintopu.com.(2020.January.26).Retriewed from https://www.eviminaltintopu.com/ tas-boyama-etkinligi/

http://bahadiricel.wordpress.com/.(2009.January.3) Retriewed from).https://bahadiricel.wordpress. com//?s=renklerin+dans\%C4\%B1 \&search=Holy dance of colors on water: Art of marbling 